\title{
Levels and criteria for understanding of the scientific text in the pre-university period
}

\section{Niveles y criterios para la comprensión del texto científico en la etapa de educación preuniversitaria}

\author{
Kharitonova Olga \\ Plekhanov Russian University of Economics, Moscow, Russian Federation \\ ORCID ID: https://orcid.org/0000-0002-2201-4142 \\ Fisenko Olga \\ Peoples' Friendship University of Russia (RUDN University), Moscow, Russian \\ Federation \\ ORCID ID: https://orcid.org/0000-0002-3824-5535 \\ Masyuk Marina \\ Peoples' Friendship University of Russia (RUDN University), Moscow, Russian \\ Federation \\ ORCID ID: https://orcid.org/0000-0002-0628-9269
}

Received 10-10-20 Revised 11-12-20 Accepted 01-13-21 On line 01-14-21

*Correspondence

Email: olfiss@list.ru
Cite as:

Kharitonova, O., Fisenko, O., \& Masyuk, M. (2021). Levels and criteria for understanding of the scientific text in the pre-university period. Propósitos y Representaciones, 9 (SPE1), e866. Doi: http://dx.doi.org/10.20511/pyr2021.v9nSPE1.866 


\section{Summary}

The article covers the issues concerning the levels and criteria of preparatory department students' understanding of the scientific text. Teaching scientific language presupposes work with scientific texts at a language proficiency level of A1. When teaching how to work with the scientific text, one should consider its pragmatic, contents and cognitive discourse functions. Understanding is a multi-level psychological category, which determines foreign students' way of reading the scientific text. Each of the levels forms certain skills of text understanding. The article proves that comprehension of the depths of meaning is one of the criteria of scientific text understanding.

Keywords: level of understanding, criteria of understanding, scientific text, pre-university period.

\section{Resumen}

En el artículo se tratan asuntos relacionados con el estudio de criterios y niveles de comprensión del texto científico por los estudiantes extranjeros de facultades preparatorias. El aprendizaje del lenguaje científico supone trabajar con un texto científico especial en el nivel A1. Cuando se aprende a trabajar con un texto científico, es necesario considerar su orientación funcionalpragmática, funcional-significativa y cognitiva-discursiva. La comprensión representa una categoría psicológica de múltiples niveles que determina la naturaleza de la lectura de un texto científico por parte de los estudiantes extranjeros. En todos los niveles designados se desarrollan determinadas aptitudes y habilidades para comprender el texto. Está comprobado que el criterio para comprender un texto científico es la comprensión de su significado profundo por parte de los estudiantes extranjeros.

Palabras clave: niveles de comprensión, criterios de comprensión, conocimientos científicos.

\section{Introduction}

As a scientific category, understanding has been a subject under scrutiny of psychologists since the mid-twentieth century. Originally, the scholars studied the specifics of understanding as a process and the interrelations between understanding and the individual psychological traits of the one who understands (Levieva 1957; Slavina 1968; Chukhin 1956). The issue of criteria for text understanding was inevitable. A.A. Smirnov and N.A. Menchinskaya (1962) tried to generalize such criteria. They consider the ability of verbalize the understood the basic criterion of text understanding. Moreover, the criteria of text understanding include synthesis and analysis of the material. The most reliable criterion is the ability to reproduce the text as close to the source as possible.

Further researches on understanding are linked to the study of interrelation between understanding and age (Badulin 1960; Blonskiy 1979).

Yu.K. Kornilov (1979), N.G. Molyako (1978), L.V. Putlyaeva (1985) and many other scholars pointed at the need for development of criteria for understanding and studying the problems of psychological diagnostics of understanding. The researches on levels and criteria for understanding were based on the definition of a text as a multi-level process in the unity of its language and content aspects.

The models of text reproduction were thoroughly and comprehensively studied by T.V. Akhutina (1981), L.S. Vygotsky (1985), A.R. Luria (1979), A.M. Shakhnarovich (2000). However, despite numerous studies on understanding, there is still no common understanding of this psychological category. Additionally, there is no clear distinction among the notions of understanding, cognitive process and the result of cognitive process.

The new stage of studying the notion of understanding is caused by a developing methodology of teaching Russian as a foreign language in the pre-university period. The processes of understanding are now studied in the context of teaching Russian as a foreign language (reading, speaking and listening). That is why there comes the need for defining the term of understanding as a result, as well as the need to find out what is happening in the mind of 
a subject of an educational process when understanding anything, what understanding results in and is expressed by.

\section{Problem statement}

The pre-university period is an important stage in the formation of the secondary language personality among preparatory department foreign students. Their further education at university depends on the successfulness at this stage.

Clearly, every foreigner who comes to Russia already has an established system of text understanding. Nonetheless, foreign students experience particular difficulties when understanding the read or heard texts at the scientific language lessons, as "without understanding, the comprehension of any knowledge or ways of activities hardly has any value" (Bershadskiy 2004, p.9). That is why methodologists are to study levels and criteria for understanding of the scientific text.

One of the current objectives of language teaching in the pre-university period is to form the ability "to extract, understand, transfer and effectively use the textual information obtained in different ways in everyday life, professional and social areas" (Lvova 2007, p. 179). Therefore, every Russian language professor, who teaches scientific language, should pay special attention to reading for understanding.

I.A. Zimnyaya points at the necessity of teaching the methods of work with texts. She believes that the ability to work with texts is the premise and the basis of students' independent study (Zimnyaya 2010, p. 296). Teaching methods and techniques of work with the text provides its better understanding. The theoretical research of scientific literature has demonstrated that the least studied issue is the criteria of understanding as the most important methods of academic work and the main guidelines of educational goals.

\section{Discussion}

\section{The notion of the text in psychological studies}

The text is an integrative unit of different sciences. The psychologists' interest in text studies is caused by the development of text understanding theory. I.R. Galperin defines the text as "the result of a speech-producing process, which is completed, represented in a form of a written document, literary processed according to its type, composed of a name (a title) and a number of specific units (discourses) united with different types of lexical, grammatical, logical and stylistic relations, with a certain purpose and a pragmatical setting" (Galperin 1974, p. 18). Structural components of the text and its speech-reproducing nature provide preconditions for the psychopedagogical studies. Its structure and content completeness is important as well. According to L.M. Loseva, structure and content completeness and the written form are the key attributes of the text. The text is "a message in a written form which contains structure and content completeness and the author's attitude to the message" (Loseva 1980, p. 4). It is a comprehensive framework with integral characteristics. A.I. Novikov supposes that the text "should be understood as a unity of its external and internal forms, hence, it is a discourse with interacting and mutually integrating linguistic, verbal and thinking components" (Novikov 1983, p. 30). V.N. Meshcheryakov emphasized the recipient - a reader and a listener. The text is "the result of motivated and focused verbal activity, represented in a specific verbal form and addressed to a reader or a listener" (Meshcheryakov 2011, p.39). Thus, the text is the result of an author's activity and a material for an interpreting reader. N.S. Bolotnova also pointed out at the conceptual aspect of the text, which she defines as "the product of verbal act, which has a concept (an idea) and a communication focus in the context of a specific communication sphere, as well as informative and pragmatic unit (which may be zero)" (Bolotnova 2007, p. 104). Therefore, the structure of the text is determined with its form. It consists of lexical, audial and grammatical subsystems. It is characterized by definiteness, divisibility, regularity and integrity. 
The hierarchy of the text is determined by the purposes of speech reproduction. As the text consists of numerous components, one should study them in order to analyze the text itself. Text understanding is a complex verbal activity which reflects a subject's psychological characteristics and linguistic competence. Language proficiency provides understanding. As an extralinguistic category, understanding familiarizes the listeners with the phenomena of objective reality. "As a complex sign and an integral communication unit, the text is a system of meaning units, united into a coherent closed hierarchic communicative-cognitive structure by an overall concept or idea (communicative intention) of communication participants with a specific communication purpose" (Dridze 1984, p. 71). The main idea of the text is expressed in facts and keywords. "The author orders the text in its whole, with its parameters and components, in a way that provides as flexible and information-rich structure as possible, which get gradually maintained in the communicative act, following the author's intention. That is why the meaningful and the formal aspects of the text are logical rather than chaotic or random" (Klementsova 1988, p. 34). I.R. Galperin identifies three types of information according to a pragmatical objective:

1) factual information reflects the facts, events and processes in the past or in the future;

2) conceptual information represents an author's personal attitude to the facts in the text. This information may be expressed unclearly and is not equal to the message;

3) subtextual information has no verbal expression. It reproduces additional hidden meanings which become clear after re-reading. Subtextual information depends on a reader's thesaurus. Subtextual information may be situational due to the facts, described in novels and stories, and associative, owing to the associations of the reader (Galperin 1981, p.28-45).

To sum up, the Russian psychology studies consider the text a communicatively important structure and content unit, based on a conceptual field, determining potential ways to understand the text with the help of personal life experience and conceptual scientific knowledge (true or false).

\section{Scientific text}

The scientific text is a complex sign reflecting science-based, valid and reliable knowledge. The preparatory department students' skills of processing scientific texts are formed at A1 level. In this period foreign students learn how to work with scientific texts. The cognitive structure of the text can only be revealed with the triade of author-text-off text reality.

The author is a meaning-bearing component as it is the author who determines the form, the structure and the content of the scientific text. To organize an educational process aimed at understanding the structure of the scientific text and its content one must take into consideration its specifics. The main characteristics of the scientific text are:

1) Functional pragmatic focus. The scientific text is a means of saving scientific knowledge. It represents theoretical and practical cognitive experience in a verbal form. The scientific text is devised to convince the recipient in the validity of scientific knowledge.

2) Functional informative focus. The scientific text is characterized by logic of information. The more accurate the statement, the more logical the presentation of scientific knowledge. For better understanding of scientific texts such illustrations as figures, schemes, photos, etc. are used.

Concentrical presentation is another characteristic of the scientific text; "concentrical presentation of material/information means that a term, a fact or a phenomenon are explained, specified and supplemented with new details" (Rogava 1983, p. 3).

The increasing amount of information about the same term provides a more profound cognition of its idea.

Divisibility of the scientific text is a crucial characteristic, represented in a specific structure of the scientific text.

The scientific text is a sequence of relatively independent texts with a specific inner structure in its core. Such texts include sections, paragraphs, or textbook chapters. Each component of the scientific text contains cognitive-discursive function.

Coherence is another characteristic of the scientific text. It is achieved through the use of terminology. The key terms show the semantical and formal coherence of the scientific text. 
At the level of meaning the coherence of the scientific text is linked to the logic of text presentation.

The scientific text contains the author's interpretation of its causality. Along with the other means, conceptual metaphor provides the text coherence (Kolotnina 2001, p.17). Imagery and emotionality have an informative function: "no matter how profound the emotional function is implemented in the scientific text, it always follows the main objective, which is to implement informative function, for emotional function only helps the author to provide more convincing evidence for their view and make a recipient believe a speaker" (Novoselova \& Turuk 1989, p. 89). To convince the recipients, the authors of scientific texts use methods of metaphor modelling.

3) cognitive-discursive focus.

This aspect is developed by E.S. Kubryakova and her scientific school. It is based on the issue of scientific text understanding, i.e. the idea of scientific text structure and characteristics that should be considered in the meaningful analysis of the scientific text.

In this context, a mental model underlying the text is reconstruction. The cognitive aspect is related to the idea of the language as a means of cognitive activity and mental processes linked to cognitive abilities (Kubryakova 2001, p. 12-13).

According to cognitive studies, the scientific text is viewed from the point of scientific knowledge characterized with a number of specifics. Knowledge becomes systematic when separate fragments of the scientific text are interrelated and methodologically sound. Scientific knowledge must be valid, evidence-based and open to debate. Scientific knowledge reflects the system of knowledge both as a separate science and knowledge in mental structures.

The cognitive approach to the scientific text requires the analysis of the information implied in the moment of text's reproduction and the idea of text processing operations, necessary for extraction of specific knowledge from the scientific text. It helps to identify the correspondence between text units and the coded information in them.

\section{Understanding as psychological category determining focused reading in the pre- university period}

Processing the scientific text in the pre-university period is related to the search for the optimal ways of teaching Russian as a foreign language. They include attempts to identify the levels and criteria for foreign students' understanding of the scientific text.

The theoretical attempts to generalize the understanding theories were made by Russian scholars A.A. Smirnov and N.A. Menchinskaya (1962). They concluded from their empirical studies that reproduction of the text close to the source is less reliable than answers to the questions and generalized retelling of the text in own words.

On analyzing understanding in the philosophic and psychological aspect, A.A. Brudny gives the following definitions of the word 'understanding':

1) "following a determined or chosen direction";

2) "the ability to predict";

3) "the ability to give a verbal equivalent";

4) "coordination of activity programs";

5) "solving problems";

6) "the ability to give an appropriate reaction";

7) "a realized ability to reason correctly" (Brudny 1975, p. 111).

The researchers concluded that understanding is a complex mental process aimed at revealing the relations, attributes and linkages of reality objects. Nevertheless, Russian psychological studies have paid little attention to the criteria of understanding for a long time.

The indicators of controlling the text understanding can be conditionally divided into two groups. The first one includes communicative character and presupposes:

1) the answers to the questions on the text in different forms;

2) formulation of the questions in separate sentences; 
3) retelling;

4) illustration of the text;

5) intonating.

The second group implies logical and textual analysis aimed at:

1) making word constructions with new words;

2) explaining the meaning of some words;

3) translating;

4) reading pace, etc.

Some indicators like free answers to the read text are more reliable, while such indicators as ready answers to the questions, retelling and reading pace are less reliable.

Therefore, psychopedagogical literature has established a notion of understanding as a cognitive process and as its result. In the late 1990s psychologists agreed on the need to consider understanding as a category, closely linked to the meaning. For instance, L.L. Gurova (1986) supposes that understanding is a subject's establishing of the meaning. However, knowledge and understanding are not identical. The meaning has no fixed boundaries and, thus, the subject broaden it according to their cognitive abilities and needs. When reasoning the mechanisms of understanding, L.L. Gurova comes to a conclusion that communication should be studied and specified. The effectiveness implies correspondence between general knowledge and understanding of the related specific situation (Gurova 1986).

According to V.V. Znakov, understanding of knowledge produces its operational meaning and a cognitive attitude to it. That is, an individual understands the objective reality reflected by knowledge rather than knowledge itself. Hence, knowledge is rather a means of understanding rather than its objective. By converting the reflection of a real object, the subject transcends its borders (Znakov 1994, p. 56-68). Thus, understanding is a complex cognitive mental process aimed at revealing the relations, attributes and linkages of reality objects. The subject of understanding is a person, while phenomena and objects of the reality are its object.

The process of text understanding is a hierarchical structure including the lower (sensory) and upper (meaningful) levels. The process of text understanding, as N.I. Zhinkin believes, is related to a paraphrase or substitution with their verbal equivalents. A simple signal or a visual are intermediaries of text comprehension (Zhinkin 1961).

The process of text comprehension presupposes a transmission from the interpretation of separate words to understanding of phrases, statements and the idea of the text. N.I. Zhinkin points out at the complementary role of separate words and phrases as the recipient never aims at their understanding. Understanding begins with searching for the general meaning of the message and making assumptions, then the recipient goes to a lower level: speech recognition (sensory level), comprehension of separate words (lexical level), and comprehension of sentences and their meanings (syntax level) (Zhinkin 1958, p. 53). Hence, the process of text understanding and the order of comprehending information do not coincide. The level of adequate comprehension of a statement is possible only in case of an imagery interrelation of these levels.

\section{Formation of skills of conscious reading of the scientific text in the pre-university period}

Contemporary psychopedagogical studies consider reading as a specific type of speech production.

The theory of speech production is closely linked to Vygotsky's study of inner speech. L.V. Shcherba was one of the first scholars who tried to identify the structure of speech production, naming three aspects of linguistic phenomena:

1) speech production (speaking and understanding);

2) language system (dictionaries, grammar);

3) language material (a sum of the spoken and the understood).

V.V. Vinogradov continued developing Shcherba's ideas, claiming that the idea of a language as a system of interrelated categories cannot fully reflect the diversity of speech phenomena and forms (Vinogradov 1991, p. 10-11). 
A.A. Leontyev (1969) pointed out at the interrelation of the language and the thought. Speculating on the language and the speech, he came to the following conclusions:

1) speech is not a manifestation of the language;

2) speech is structurally and functionally diverse;

3) speech production has its own specifics in linguistics, psychology, etc. (Leontyev 1969).

I.A. Zimnyaya explains the integrity of the language and the speech with the specifics of their relation to a person's cognitive and communicative activity (Zimnyaya 2010, p. 45)

Nonetheless, it would be wrong to contrast the language and the speech because they coexist rather than exclude each other. As A.A. Potebnya stated, the language is a means for creation of a thought (1958).

Hence, the process of teaching Russian as a foreign language presupposes teaching the language in the process of speech production. Reading has educational, intellectual, entertaining, informative, cognitive, communicative, practical, professional and political ideological functions.

Conscious reading is a prior objective which requires a certain psychological disposition.

Reading a text at Level A1 implies the following stages:

1) Preliminary orientation. The subject of educational process answers the question "Why read?" Preparatory department students are to get involved in reading, comprehending the practical use of the tasks. The key objective of reading a scientific text is a detailed text analysis. However, in case of a given reading aim the key objective may change. The professor is to manage it at scientific language lessons.

2) Planning is related to the answer to the question "How to read?" The foreign students apply their knowledge and skills related to the upcoming reading of scientific texts.

3) Plan implementation is related to reading and understanding techniques. The arsenal of techniques and methods is determined by the pedagogue according to foreign students' Russian language proficiency.

4) Analysis of the results depends on the key objective of reading. Reading a text presupposes mechanisms of inner articulation of the read texts. The reader sees the text, articulates it and hears themselves from the outside.

Prediction is related to word guessing, guessing syntax from first words in the sentence, and guessing the content from the heading.

It is advisable to use different reading methods and techniques at lessons. For example, depending on a reading pace there are speed-reading (dynamic reading) and traditional reading. Depending on a reading technique there is reading loud and silent reading. When speed-reading, "a person extracts meaningful information from the text at a higher speed" (Kuznetsov \& Khromov 1983, p. 18).

Reading can be educational, related to the formation of reading skills, or real as a means of communication and cognition.

Educational reading can be introductory, scanning or analyzing. Educational (analyzing) reading forms reading skills. Its scope is a profound text understanding. Introductory reading focuses mental structures on understanding of the main message. Scanning reading gives the reader a general idea of the content.

Consider the levels of understanding the scientific text.

1) The first (introductory) level forms the skill of conscious reading.

2) The second level is aimed at identification of informative core in the sentence, the topic, thematic groups (in the context of coherent scientific text). The method of question formulation is closely linked to the methods of comprehending the heading, anticipation and recipation.

By highlighting the keywords and conceptually important sentences, along with structurecontent division of the scientific text foreign students manage to understand its structure-content aspect. A nominative plan and the ways of text compression also provide understanding.

Comprehending the text forms motivation to study. Conscious reading is impossible without reflection. It is appropriate here to mention philological reflection which is "a specific and always conscious process when a person reflects over the structure, the attributes, style and genre characteristics of the text and extracts new information about it, thus, understands it" 
(Zemskaya et al. 2010: p. 191). It means that reflection is considered to be a conscious process of reading when a reader identifies the way they understands the text.

After the comprehension of the text the students are ready for the further comprehensions of the learning material. They exercise the basic skills of text understanding (L.P. Doblaev, G.G. Granik) - formulation of the questions on the text.

The method of "asking questions - finding answers" helps to ask factual and problematic questions.

While factual questions are aimed at finding out the factual information, problematic questions are focused on conceptual and sub-textual information. For example, the tasks, aimed at work with the text containing questions, are focused on the identification of the key facts. The questions may be:

1) simple (naming the facts, reproducing information);

2) explanatory (establishing causality, starting with "Why");

3) creative (containing the component of conditional);

4) evaluative (related to the criteria of assessment, etc.);

5) practical (related to the establishment of interrelation between theory and practice).

The formation of text understanding may be provided with an extensive system of pretextual and textual exercises. At first preparatory department students get familiarized with new words related to the topic of the unit. Identification of lexical thematic group is a method of text understanding. Derivational models help to identify the generic terms and specific terms.

The method of highlighting keywords in the text provides the formation of superficial and profound meanings. The students are to identify the meaning of a new term. Keywords in the scientific text have a specific syntax function; they are repeated in the first sentence and can unfold the conceptual information. Keywords are the intermediary between the superficial and profound meaning due to their conceptuality. The profound meaning of the text requires preparatory department students' bigger mental efforts. The students devise a strategy of the dialog with the author. The foreign students need a sort of linguistic and scientific competences here. The comprehension of profound meaning results in a meaningful scheme of the text. Teaching how to understand the read scientific text is ended in familiarizing with the tactics of identifying the problems of the text and the author's attitude to them.

\section{Conclusiones}

The research has demonstrated that the problem of understanding the scientific knowledge is of great relevance for the preparatory department students who attend scientific language course. The study of scientific text understanding is related to the comprehension of its form and structure. As a linguistic and extralinguistic phenomenon, the text is a way of implementing the language system, the form of retaining and transmission of information, the way of reflecting psychic and intellectual spheres oa a person's activity.

To understand the scientific text is a challenge which may be overcome with the help of those who teach Russian as a foreign language.

When teaching foreign students how to read, the professor:

1) conducts the work aimed at higher motivation to study;

2) teaches text understanding methods and techniques;

3 ) increases the level of self-independence in the use of text understanding methods and techniques.

The analysis of psychological theories has proved that there is little attention to the levels and criteria for understanding as the basis of teaching text understanding for foreign students. However, it is levels and criteria for understanding that should determine the modus operandi of the scientific text in the pre-university period.

\section{References}

Akhutina, T.V. (1981) Organization of a person's vocabulary according to aphasia vocabulary. Psycholinguistic lexical and phonetical studies. Kalinin, Russia, 3-12

Asmolov, A.G. \& Volodarskaya, I.A. \& Burmenskaya, G.V. (2011) Formation of universal 
educational actions at school: from actions to thoughts. The system of exercises: a teacher's book. Ed.: A.G. Asmolov. Moscow, Russia, 159

Badulin, V.T. (1960) Development of schoolchildren's understanding the metaphors in the fables (II-IV grades). Scientific notes of Kostroma State University. No 7, Kostroma, Russia, 213248

Bershadsky, M.E. (2004) Understanding as a pedagogical category. (Monitoring of cognitive sphere: do pupils understand what they study?). Moscow, Russia, 176

Blonsky, P.P. (1979) Development of a pupil's thought. Selected psychological and pedagogical works in two volumes. Vol. 2, Moscow, Russia, 5-117

Bolotnova, N.S. (2007) Philological text analysis: a textbook. Moscow, Russia, 520

Brudny, A.A. (1975) Understanding as a philosophical and psychological problem. The problems of philosophy. No 10, 109-117

Chukhin, A.I. (1950 Speech understanding of 3-year-old children in the senior group of nursery schools. Bulletin of Crimean Pedagogical Institute. Vol. 15, Simferopol, Russia, 47-91

Doblaev, L.P. (1982) Meaningful structure of a learning text and the problems of understanding. Moscow, Russia, 176

Dridze, T.M. (1980) Language and social psychology. Moscow, Russia, 224

Galperin, I.R. (1980) Integration and completeness of the text. The Bulletin of the Russian Academy of Sciences: Studies in Literature and Language. Vol.39. No 6, 512-521

Galperin, I.R. (1981) Text as an object of linguistic studies. Moscow, Russia, 139

Granik, G.G. \& Bondarenko, S.M. \& Kontseva L.A. (1991) When a book teaches. Moscow, Russia, 256

Gurova L.L. (1986) The processes of understanding in thought, communication and practical activity. Thought, communication, practice. Collection of academic papers. Yaroslavl, Russia, 97-108

Klementsova, N.N. (1988) Meaningful structure of the text and its understanding. Text in speech (translation and linguistic analysis. Moscow, Russia, 34-39

Kolotnina, E.V. (2001) Metaphory modelling of reality in Russian and English economic discourse. Abstract from thesis. Ekaterinburg, Russia, 19

Kornilov, Yu.K. (1979) Psychological problems of understanding. Yaroslavl, Russia, 80

Kubryakova, E.S. (2001) The problem of relevant meaning of word-formation theory (at the turn of the century): materials from international conference, devoted to M.D. Stepanova's endeavor and its development on the 100th anniversary. Moscow, Russia, 11-18

Kuznetsov, O.A. \& Khromov, L.N. (1983) Speed-reading method. Moscow, Russia, 17

Leontyev, A.A. (1969) Language, speech and speech reproduction. Moscow, Prosveshcheniye, 211

Levieva, S.N. (1957) Eighth-grade pupils' understanding of fictional character. Voprosy Psychologii. No 3, 63-71

Loseva, L.M. (1980) Text structure. Moscow, Russia, 96

Luria, A.R. (1979) Language and Cognition. Moscow, Russia, 319

Lvov, M.R. (2007) Russian at school: the history of teaching. Lecture course for pedagogical college and university students. Moscow, Russia, 331

Meshcheryakov, V.N. (2011) Creative potential of the text theory and text production theory. Language, culture, personality: the development of students' creative potential among via Russian: material from International Scientific-Practical Conference (17-18.03.2011). Moscow, Russia, 39-48 $55-63$

Molyako, N.G. (1979) Psychological structure of engineering. Voprosy Psychologii. No 4,

Novikov, A.I. (1983) Semantics of the text and the ways of its formalizing (based on scientific and technical texts): a thesis. Moscow, 1983, 342

Novoselova, I.Z. \& Turuk, I.F. (1989) Aspects of classification for scientific texts. Semantical structure of the text and its components: inter-university collection of academic papers. Kaliningrad, Russia, 88-91 
Putlyaeva, L.V. (1985) The processes of understanding and the hypothesis in dealing with technical issues. Voprosy Psychologii. Moscow, Russia, 37-49

Rogava, M.D. (1983) Linguistic and stylistic specifics of English educational literature in Humanities departments (based on the material from British and US textbooks): Abstract from the thesis. Moscow, Russia, 21

Shakhnarovich, A.M. (2000) Text as a phenomenon of linguistic cognition. Linguistic cognition, content and functioning: XIII International Psycholinguistics and Communication Theory symposium. Moscow, Russia, 273-275

Shcherba, L.V. (1974) Language system and speech production. Leningrad, Russia, 428

Slavina, L.S. (1947) Young children's understanding of storytelling. APS USSR Bulletin. No 7. Moscow, Russia, 41-78

Smirnov, A.A. \& Menchinskaya, N.A. (1962) Understanding. Psychology: a textbook for pedagogical institutes. Moscow, chpedgiz Publ., 1962, pp. 263-266

Vygotsky, L.S. (1985) Thought and speech. Collection of works in 6 volumes. Vol. 3. Moscow, Russia, 295-361

Zemskaya, Yu.N. \& Komissarova, L.M. \& Panchenko, N.V. \& Chuvakin, A.A. (2010) Text theory. Moscow, Russia, 384

Zhinkin, N.I. (1958) Speech mechanisms. Moscow, Russia, 370

Zimnyaya, I.A. (2001) Educational psychology. Moscow; Voronezh, Russia, 448

Znakov, V.V. (1994) Understanding in cognition and communication. Moscow, Russia, 236

*The publication has been with the support of the "RUDN University Program 5-100". 